\title{
A DESINFORMAÇÃO NO PROCESSO ELETRÔNICO DE VOTAÇÃO: UMA ANÁLISE SOB O ASPECTO DA COMPETÊNCIA INFORMACIONAL DO INDIVÍDUO ${ }^{1}$
}

\section{DISINFORMATION IN THE ELECTRONIC VOTING PROCESS: AN ANALYSIS UNDER THE ASPECT OF THE INDIVIDUAL'S INFORMATIONAL COMPETENCE}

\author{
João Henrique Koerig²
}

\author{
Submetido: 25/02/2021 \\ Aprovado: 09/03/2021
}

\begin{abstract}
RESUMO
A democracia pressupõe a participação das pessoas em processos decisórios que, em alguma medida, afetam individual e/ou coletivamente suas vidas. Um dos pilares da democracia representativa é a liberdade de expressão, concebida como direito fundamental que, no contexto constitucional brasileiro, garante aos cidadãos a "livre manifestação do pensamento. " Outro sustentáculo, não menos importante, é o direito à informação, igualmente protegido pela Constituição Federal, que garante às pessoas o acesso aos conteúdos informacionais de interesse individual e coletivo. Mas o que acontece quando a liberdade de expressão é usada para disseminar informações falsas? E quando esse processo corrompido se utiliza das facilidades tecnológicas e da falta de competência informacional dos usuários para propagar a desinformação no país? É nesse contexto que o sistema de votação eletrônica vem sofrendo ataques constantes, sobretudo no ambiente das redes sociais. O presente artigo tem por objetivo geral mapear os artigos acadêmicos que se debruçam sobre as temáticas: competência informacional, desinformação e fake news, além dos objetivos específicos: contextualizar a temática competência informacional e desinformação, identificar ações já desenvolvidas de combate à desinformação no sistema de votação eletrônica brasileiro, e, propor iniciativas educacionais para o seu fortalecimento. A coleta foi realizada no portal Google Acadêmico, utilizando-se os termos "competência em informação", "desinformação", "fake news, além de "democracia", "votação eletrônica" e "urna eletrônica", nos idiomas português, inglês e espanhol. Por fim, apresentou uma proposta para estimular a iniciativa educacional no âmbito dos Tribunais Regionais Eleitorais.
\end{abstract}

PALAVRAS-CHAVE: Fake News. Desinformação. Competência em Informação. Eleições. Sistema de votação eletrônica. Democracia.

\begin{abstract}
Democracy presupposes the participation of people in decision-making processes that, to some extent, affect their lives individually and/or collectively. One of the pillars of representative democracy is freedom of expression, conceived as a fundamental right that, in the Brazilian constitutional context, guarantees citizens the "free expression of thought." Another support, no less important, is the right to information, also protected by the Federal Constitution, which guarantees people access to informational content of individual and collective interest. But what happens when free speech is used to spread false information? And when this corrupted process uses technological facilities and the lack of informational competence of users to spread misinformation in the country? It is in this context that the electronic voting system has been under constant attack, especially in the social media environment. The general objective of this article is to map academic articles that focus on informational competence, disinformation and fake news, in addition to specific objectives: to contextualize informational competence and disinformation, to identify actions already taken to combat disinformation in the brazilian electronic voting system, and, to propose educational initiatives

\footnotetext{
1 Artigo desenvolvido para avaliação final da disciplina Gestão da Informação e do Conhecimento, ministrado pela professora Dra. Andrea Vasconcelos Carvalho, no semestre 2020.1.

2 Mestrando do Programa de Pós-graduação em Gestão da Informação e do Conhecimento (PPGIC) da Universidade Federal do Rio Grande do Norte (UFRN).
} 


\section{RECIMA21 - REVISTA CIENTÍFICA MULTIDISCIPLINAR}

A DESINFORMAÇÃO NO PROCESSO ELETRÔNICO DE VOTAÇÃO: UMA ANÁLISE SOB O ASPECTO DA COMPETÊNCIA INFORMACIONAL DO INDIVÍDUO João Henrique Koerig for its strengthening. The collection was carried out on the Google Scholar portal, using the terms "information competence", "disinformation", "fake news", in addition to "democracy ", "electronic voting" and "electronic ballot box", in Portuguese, English and Spanish. Finally, it presented a proposal to stimulate the educational initiative within the scope of the Brazilian Electoral Courts.

KEYWORDS: Fake News. Disinformation. Information Literacy. Elections. Electronic voting system. Democracy.

\section{INTRODUÇÃO}

Em 2018, nas vésperas das eleições gerais, o candidato que liderava as pesquisas de intenção de votos para a presidência do Brasil, assim, se pronunciou: "pelo que eu vejo nas ruas, não aceito resultado das eleições diferente da minha eleição." (BOLSONARO, 2018 apud G1, 2018, online). Após a divulgação do resultado que the consagrou vencedor do pleito, já empossado no cargo, disparou: "[...] pelas provas que tenho em minhas mãos, que vou mostrar brevemente, eu tinha sido, eu fui eleito no primeiro turno, mas, no meu entender, teve fraude", e completou dizendo: "nós precisamos aprovar no Brasil um sistema seguro de apuração de votos, caso contrário, [é] passível de manipulação e de fraudes." (BOLSONARO, 2020 apud SANCHES, 2020, online)

É nesse ambiente de forte ataque à confiabilidade do sistema de votação eletrônica, surpreendentemente liderado pelo chefe do executivo federal, que a desinformação, impulsionada pelas redes sociais, ameaça não apenas a legitimidade das eleições brasileiras, mas a própria democracia no país.

Como ponto de partida, é importante ressaltar que a resposta do órgão máximo da justiça eleitoral brasileira, frente às supostas fragilidades do sistema, foi a determinação de prazo para que fossem apresentadas provas das aventadas violações. O prazo transcorreu e as alegadas provas nunca apareceram.

Somam-se a esse episódio, outros tantos relatos de possíveis ataques hackers à urna eletrônica, de supostos eleitores votando mais de uma vez, de situações hipotéticas em que, "ao se digitar o número de candidato $X$, a urna apresentou candidato $Y$ ". O fenômeno informacional que se configura não é novidade no ambiente político; o que se observa é o aumento expressivo dessas manobras de distorção, descontextualização e falsificação da informação. Melhor dizendo, é o uso de informação sabidamente errada para construir e/ou reforçar narrativas político-ideológicas em favor de determinado grupo. Nesse cenário, é importante que as instituições democráticas invistam em educação para o desenvolvimento de competências informacionais do cidadão, cumprindo à Justiça Eleitoral liderar ações de enfrentamento às práticas de desinformação no âmbito das eleições, bem como ações pedagógicas de conscientização dos avanços democráticos advindos do processo de votação eletrônica. É dizer: não adianta oferecer segurança, celeridade e transparência, por mais robustas que sejam, se tais benefícios estão sendo ofuscados pela "fumaça da desinformação". O 


\section{RECIMA21 - REVISTA CIENTÍFICA MULTIDISCIPLINAR}

A DESINFORMAÇÃO NO PROCESSO ELETRÔNICO DE VOTAÇÃO: UMA ANÁLISE SOB O ASPECTO DA COMPETÊNCIA INFORMACIONAL DO INDIVÍDUO João Henrique Koerig processo de educação informacional precisa ser contínuo, assim como contínua é a natureza do processo democrático.

Portanto, é dever das instituições salvaguardarem a própria democracia para não permitirem que a mesma sucumba às narrativas de ocasião. É nesse sentido que o presente artigo tem por objetivo geral analisar a desinformação nas eleições brasileiras sob a ótica da gestão da informação e do conhecimento, além dos objetivos específicos: contextualizar a temática competência informacional e desinformação, mapear artigos acadêmicos que se debruçam sobre os temas competência informacional, desinformação e Fake News, identificar ações já desenvolvidas de combate à desinformação no sistema de votação eletrônica brasileiro, e, propor iniciativas educacionais para o seu fortalecimento. Para isso, os dados foram coletados no período de 21 de dezembro de 2020 a 1 de janeiro de 2021, no portal Google Acadêmico, utilizando-se os termos "competência em informação", "desinformação", "Fake News", além de "democracia", "votação eletrônica" e "urna eletrônica", nos idiomas português, inglês e espanhol.

A escolha por concentrar a pesquisa no referido portal se deu pelo fato de que aqui se pretende demonstrar a relevância temática a partir da análise quantitativa dos resultados; sendo o Google Acadêmico o portal que concentra maior capacidade de recuperação terminológica.

A relevância social da presente pesquisa é observada no que tange à ameaça da democracia diante do uso da desinformação como ferramenta para seu enfraquecimento. O interesse pelas questões que envolvem a desinformação no processo de votação não permite que haja aqui a pretensão em aprofundar os temas "competência informacional” e "desinformação", mas, carrega a intensão de oferecer um recorte que permita a discussão desses assuntos no contexto da votação eletrônica.

Assim, este artigo está estruturado da seguinte forma: na introdução são expostas a contextualização do tema, as justificativas e objetivos da pesquisa; na segunda seção, no referencial teórico, é feita uma explanação acerca da Gestão da Informação e do Conhecimento destacando-se alguns dos principais teóricos em GIC, discorrendo sobre a questão da competência informacional dos indivíduos e possíveis consequências da sua falta, sobretudo no que diz respeito ao avanço da desinformação.

O terceiro capítulo apresenta o percurso histórico do sistema de votação eletrônica do Brasil, seus avanços e desafios, bem como o aumento da desinformação como arma de enfraquecimento democrático. Também são apresentados resultados da presente pesquisa bibliográfica, de metodologia exploratória, para aferição do número de trabalhos acadêmicos relativos aos temas aqui abordados, bem como o levantamento de ações institucionais de enfrentamento da problemática da desinformação no processo de votação. Por fim, nas considerações finais, apresenta-se uma proposta de iniciativa de educação informacional no âmbito da Justiça Eleitoral. 


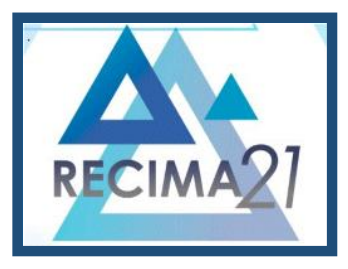

\section{RECIMA21 - REVISTA CIENTÍFICA MULTIDISCIPLINAR}

A DESINFORMAÇÃO NO PROCESSO ELETRÔNICO DE VOTAÇÃO: UMA ANÁLISE SOB O ASPECTO DA COMPETÊNCIA INFORMACIONAL DO INDIVÍDUO 2 A GESTÃO DA INFORMAÇÃO E DO CONHECIMENTO.

Reconhecida como subárea da Ciência da Informação, a Gestão da Informação e do Conhecimento tem sua origem em estudos norte-americanos (embora inicialmente fora do escopo da information science) e desenvolvimento em diferentes contextos, destacando-se, principalmente, o Canadá (FERREIRA; NEVES, 2003 apud ARAÚJO, 2014).

Barbosa (2008), assevera que devido à sua crescente importância para as organizações contemporâneas, a informação e o conhecimento têm merecido, cada vez mais, a atenção de gestores, profissionais e pesquisadores.

No entendimento de Souza, Dias e Nassif (2011, p. 67-68)

A gestão da informação e do conhecimento se apresenta como um complexo de gestão de processos, que, em última análise, promovem o desenvolvimento de competências em informação e conhecimento, nas diversas esferas organizacionais, possibilitando a criatividade e a competitividade.

Teóricos relevantes da ciência da informação, como Davenport e Prusak (1998, p. 18), se ocuparam de forma pertinente em conceituar e correlacionar dados, informação e conhecimento, afirmando que dados "são simples observações sobre o estado do mundo, [...] de fácil estruturação, facilmente obtidos por máquinas, frequentemente quantificados e facilmente transferidos"; informação como "dados dotados de relevância e propósito", ou seja, para ser informação é necessária análise, exigindo consenso em relação ao significado e, obrigatoriamente, a mediação humana. Já o conhecimento "reside na mente humana, inclui reflexão, síntese e contexto, é de difícil estruturação, transferência e captura em máquinas e é frequentemente tácito. "

Do estudo da GIC e seus desdobramentos interdisciplinares com outras áreas do conhecimento, observa-se a importância do tema, sobretudo ao se considerar a sociedade contemporânea como sociedade da informação e do conhecimento. A quantidade de informação, bem como as facilidades de acesso e produção de conteúdo, transformou o mundo em que vivemos em uma verdadeira tempestade informacional. Se por um lado se observam facilitadores tecnológicos, como computadores e smartphones, que amplificam o acesso aos conteúdos informacionais dispostos na web, por outro, urge a necessidade de gerir adequadamente essa massa de informações.

O grupo de usuários da informação cresce exponencialmente, o que demonstra uma maior democratização informacional se comparada a outros momentos da história. Porém, é preciso que se leve em consideração as circunstâncias individuais de cada usuário quando do momento da busca informacional. 


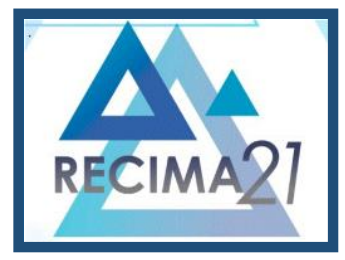

\title{
RECIMA21 - REVISTA CIENTÍFICA MULTIDISCIPLINAR
}

A DESINFORMAÇÃO NO PROCESSO ELETRÔNICO DE VOTAÇÃO: UMA ANÁLISE SOB O ASPECTO DA COMPETÊNCIA INFORMACIONAL DO INDIVÍDUO João Henrique Koerig

É nesse contexto que Detlor (2010) assevera que a gestão da informação é menos sobre resolver problemas técnicos e muito mais sobre considerar o aspecto humano da gestão informacional.

Pelo entendimento de Choo (2003), a necessidade, a busca e o uso da informação são determinados pelas demandas do trabalho e do ambiente social, pela lacuna de conhecimento do indivíduo e por sua experiência emocional. Tal componente humano também encontra guarida em Davenport (2001), quando diz que “informação e conhecimento são, essencialmente, criações humanas, e nunca seremos capazes de administrá-los se não levarmos em consideração que as pessoas desempenham, nesse cenário, um papel fundamental."

Nesse contexto, podemos inferir que a GIC se apresenta como disciplina contemporânea de perfil prático-acadêmico, posicionando-se estrategicamente, na conjuntura da sociedade atual, como ferramenta de curadoria informacional, com foco na qualidade, transparência e confiabilidade da informação e do conhecimento.

Portanto, para dar efetividade à Gestão da Informação e do Conhecimento, se faz necessário o desenvolvimento de competências informacionais nos indivíduos, tema que será abordado no capítulo subsequente.

\subsection{A Competência Informacional.}

Para Valentim (2014), a competência informacional envolve ações que possibilitam aos indivíduos desenvolver a capacidade de reconhecer uma necessidade informacional, ter a capacidade de identificar e localizar uma informação, bem como avaliar e usar efetivamente essa informação. Por isso, a sociedade contemporânea tem reconhecido a importância da competência em informação, principalmente nos países em que a exclusão social é significativa.

Hatschbach e Olinto (2008, p. 22) destacam que,

\begin{abstract}
no final da década de 1980, o Comitê Presidencial da American Library Association - ALA reconhece a importância da Competência em Informação para manutenção de uma sociedade democrática, e a conceitua de acordo com os requisitos necessários para sua aquisição. 'Para ser 'competente em informação', a pessoa deve ser capaz de reconhecer quando a informação é necessária e ter a habilidade de localizar, avaliar e usar efetivamente esta informação [...] e usar a informação de forma que os outros também possam aprender com ela' (ALA, 1989).
\end{abstract}

No Brasil, os primeiros a fazerem referência ao termo information literacy foram os bibliotecários, a partir de estudos desenvolvidos com foco na educação dos usuários, apontando-se como referência primária a professora Sônia Elisa Caregnato (2000), que traduziu o termo para "alfabetização informacional", em seu artigo intitulado "O desenvolvimento de habilidades 


\section{RECIMA21 - REVISTA CIENTÍFICA MULTIDISCIPLINAR}

A DESINFORMAÇ̃̃o NO PROCESSO ELETRÔNICO DE VOTAÇÃO: UMA ANÁLISE SOB O ASPECTO DA COMPETÊNCIA INFORMACIONAL DO INDIVÍDUO João Henrique Koerig informacionais: o papel das bibliotecas universitárias no contexto da informação digital em rede" (DUDZIAK, 2002).

Nas palavras de Valentim, Jorge e Ceretta-Soria (2014, p. 210),

As mudanças que permeiam a sociedade, bem como a velocidade como fator determinante da revolução informacional, evidenciaram a necessidade de um elemento responsável pelo processo de aprendizagem no que tange à informação, auxiliando e dinamizando o processo de geração de conhecimento, surgindo assim a necessidade de propiciar competência aos indivíduos no âmbito informacional.

A competência informacional trata-se, portanto, de um processo educacional com foco em habilidades capazes de conferir ao usuário as condições mínimas de manuseio da informação. Traçando-se novamente um paralelo com o caos informacional atual, cada vez mais acessível a diferentes grupos de usuários, entende-se a competência em informação como ferramenta central no processo de capacitação informacional das pessoas. Nesse sentido, a já mencionada democratização do acesso à informação precisa ser acompanhada de processos educativos, também democráticos. É exatamente a falta de competência em informação das pessoas que possibilita as condições ideais para a disseminação da desinformação, assunto que será tratado no capítulo subsequente.

Tais competências informacionais são propostas por Bruce (1997) sob a divisão de sete categorias, a saber:

Quadro 1 - Categorias da Competência em Informação Propostas por Bruce

\begin{tabular}{|l|l|}
\hline Categorias & Concepçães \\
\hline Categoria 1 & $\begin{array}{l}\text { Concepção baseada em tecnologias de informação: A competência em } \\
\text { informação é dependente do uso de tecnologias de informação e } \\
\text { comunicação para recuperar informações. }\end{array}$ \\
\hline Categoria 2 & $\begin{array}{l}\text { Concepção baseada em fontes de informação: A competência em } \\
\text { informação é relacionada ao conhecimento do indivíduo para acessar e } \\
\text { manusear fontes de informação. }\end{array}$ \\
\hline Categoria 3 & $\begin{array}{l}\text { Concepção baseada no processo de execução: A competência em } \\
\text { informação é relacionada à capacidade de usar informação para enfrentar } \\
\text { situaçães. O processo varia de pessoa para pessoa, assim como o } \\
\text { resultado do processo gera uma ação para a resolução de problemas ou a } \\
\text { tomada de decisão. }\end{array}$ \\
\hline Categoria 4 & $\begin{array}{l}\text { Concepção baseada no controle da informação: A competência em } \\
\text { informação é relacionada ao controle de informações por meio de } \\
\text { estruturas manuais, tecnológicas e cognitivas, visando seu armazenamento } \\
\text { e recuperação. }\end{array}$ \\
\hline Categoria 5 & $\begin{array}{l}\text { Concepção baseada na construção de conhecimento: A competência em } \\
\text { informação é compreendida a partir da construção de uma base de } \\
\text { conhecimento pessoal, formada a partir da análise crítica do que é lido. }\end{array}$ \\
\hline Categoria 6 & $\begin{array}{l}\text { Concepção baseada na extensão do conhecimento: A competência em } \\
\text { informação é compreendida a partir de perspectivas pessoais adotadas, }\end{array}$ \\
\hline
\end{tabular}




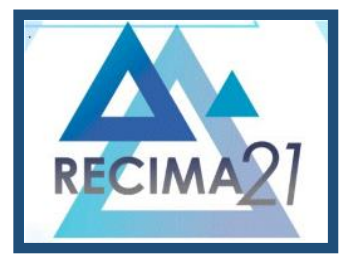

\title{
RECIMA21 - REVISTA CIENTÍFICA MULTIDISCIPLINAR
}

A DESINFORMAÇÃO NO PROCESSO ELETRÔNICO DE VOTAÇÃO: UMA ANÁLISE SOB O ASPECTO DA COMPETÊNCIA INFORMACIONAL DO INDIVÍDUO João Henrique Koerig

\begin{tabular}{|l|l|}
\hline & $\begin{array}{l}\text { como a criatividade e a intuição. Processo cognitivo interno à mente } \\
\text { humana que gera novo conhecimento ou informação. }\end{array}$ \\
\hline Categoria 7 & $\begin{array}{l}\text { Concepção baseada na sabedoria: A competência em informação é } \\
\text { compreendida a partir do uso de informações com sabedoria para o } \\
\text { benefício de outros. Envolve valores e ética pessoal. }\end{array}$ \\
\hline
\end{tabular}

Fonte: Adaptada e traduzida de Bruce (1997) apud Valentim; Jorge e Ceretta-Soria (2014, p. 210211).

Em 2018, o relatório da Comissão Europeia indicou a promoção da educação e da Competência "Infomidiática" como fator vital para reforçar a resistência da sociedade à desinformação.

\begin{abstract}
O plano de ação para a educação digital [...] salienta os riscos que a desinformação representa para os educadores e estudantes, e a premente necessidade de desenvolver as aptidões e competências digitais de todos os indivíduos, na educação formal e não formal. O quadro de competências digitais para os cidadãos, desenvolvido pela Comissão, apresenta o vasto conjunto de competências necessárias a todos, desde a Competência em informação, passando pela criação de conteúdos digitais, até à segurança e bem-estar nas redes. (COMISSÃO EUROPÉIA, 2018, p. 13-14).
\end{abstract}

Outros pesquisadores acrescentaram habilidades para definir quando uma pessoa se tornaria competente em informação. Nesta pesquisa, o que se procura demonstrar é a relação entre a falta de competência informacional e a propagação da desinformação. Se observarmos o contexto atual das famigeradas Fake News, é a carência da competência informacional no indivíduo que abre caminho para a desinformação. Tal fenômeno interfere diretamente no cotidiano das pessoas, ameaçando pilares democráticos construídos ao longo de décadas. Sua origem e potencial relação com tal carência é o que passaremos a discutir.

\subsection{Desinformação.}

De acordo com Volkoff (2004), o termo "desinformação" surgiu na Rússia (dezinformatsiya), no contexto histórico batizado de Guerra Fria, período que sucedeu a Segunda Guerra Mundial, ocasião em que Estados Unidos e União Soviética protagonizaram uma das maiores e mais duradouras polarizações vistas até hoje. As tomadas de decisões de ambas as potências eram estrategicamente planejadas, ao tempo em que buscavam ampliar seus poderes, influenciando mercados, culturas e nações inteiras. A criação, posse e disseminação de informação, bem como desinformação, eram ativos de extrema relevância político-econômica.

Como ensina Boghardt (2009), a "desinformação (dezinformatsiya) foi uma arma particularmente eficaz no arsenal de medidas ativas do bloco soviético. O termo dezinformatsiya denotava uma variedade de técnicas e atividades para fornecer informações falsas ou enganosas que os especialistas em medidas ativas do bloco soviético procuravam infiltrar na mídia estrangeira. 


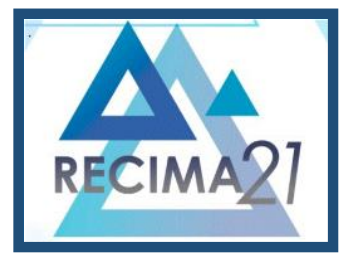

\title{
RECIMA21 - REVISTA CIENTÍFICA MULTIDISCIPLINAR
}

A DESINFORMAÇÃO NO PROCESSO ELETRÔNICO DE VOTAÇÃO: UMA ANÁLISE SOB O ASPECTO DA COMPETÊNCIA INFORMACIONAL DO INDIVÍDUO João Henrique Koerig

Do ponto de vista ocidental, a desinformação era uma mentira politicamente motivada, mas os propagandistas do bloco soviético acreditavam que suas campanhas de desinformação apenas destacavam verdades maiores ao expor a natureza real do capitalismo."

O termo em inglês, disinformation, surge pela primeira vez em 1972, quando de sua inclusão no Chambers Twentieth Century Dictionary, em Londres, onde recebe a definição "deliberate leakage of misleading information" (vazamento deliberado de informações enganosas)" (VOLKOFF, 2004).

Ao desconsiderar-se sua representação terminológica e ater-se apenas à sua prática, se percebe o uso da desinformação em diferentes contextos históricos. Darnton (2017, online) ensina que

Pietro Aretino, escritor italiano, tentou manipular a eleição do pontífice em 1522, escrevendo sonetos perversos sobre todos os candidatos menos o preferido por seus patronos, os Médicis, e os prendendo, para que todo mundo os admirasse, no busto de uma figura conhecida como II Pasquino, perto da Piazza Navona, em Roma. Os pasquins se transformaram em um método habitual para difundir notícias desagradáveis, em sua maioria falsas, sobre personagens públicos.

A Comissão Europeia (2018, p. 4) concluiu que

\begin{abstract}
a desinformação pode ser entendida como informação comprovadamente falsa ou enganadora que é criada, apresentada e divulgada para obter vantagens econômicas ou para enganar deliberadamente o público, e que é suscetível de causar um prejuízo público que abrange ameaças aos processos políticos democráticos e aos processos de elaboração de políticas, bem como a bens públicos.
\end{abstract}

Fazendo-se um rápido recorte para a atmosfera que permeia a atual política brasileira, bem como o contexto da desinformação, apontado no presente artigo como ferramenta de enfraquecimento do sistema de votação eletrônica, encontramos em Zattar (2017) uma definição adequada para o termo.: Desinformação são "[...] ações que procuram propositalmente falsificar uma informação com o objetivo de enganar as pessoas" (VOLKOFF, 2004; FALLIS, 2015 apud ZATTAR, 2017, p. 288).

A prática de desinformação remonta a diferentes períodos da história, ganhando popularidade nos últimos anos com o advento do termo Fake News, sobretudo com a eleição de Donald Trump para a presidência dos Estados Unidos, em 2016. Nas palavras de Parikh, Patil e Atrey (2019, p. 135, tradução nossa), "fake news é qualquer forma de material visual que é produzido para mudar a opinião das pessoas com relação a um indivíduo, à uma organização ou à uma crença."

\footnotetext{
${ }^{1}$ Fake news is any form of visual material that is designed and written to change people's opinion about an individual, an organization, or a belief.
} 


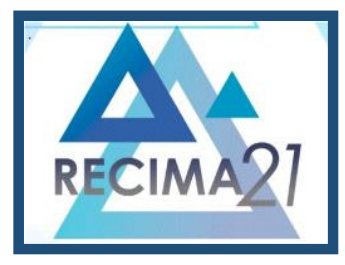

\section{RECIMA21 - REVISTA CIENTÍFICA MULTIDISCIPLINAR}

A DESINFORMAÇÃO NO PROCESSO ELETRÔNICO DE VOTAÇÃO: UMA ANÁLISE SOB O ASPECTO DA COMPETÊNCIA INFORMACIONAL DO INDIVÍDUO João Henrique Koerig

Nesse sentido, iremos analisar o resultado da pesquisa realizada no Google Acadêmico, em 22 de dezembro de 2020. Ao se pesquisar os termos "information literacy", "misinformation" "disinformation", "alfabetización informacional” "desinformación”, "competência em informação" e "desinformação", separadamente, observa-se a relevância da temática no contexto atual da sociedade da informação. O quadro 2 apresenta o resultado desta pesquisa bibliográfica.

Quadro 2 - Resultado da busca para os termos "information literacy", "misinformation" "disinformation”, "alfabetización informacional” "desinformación”, "competência em informação" e "desinformação", separadamente.

\begin{tabular}{|c|c|}
\hline Termo & Resultado \\
\hline Information Literacy & 207.000 \\
\hline Misinformation & 237.000 \\
\hline Disinformation & 92.400 \\
\hline Alfabetización Informacional & 10.800 \\
\hline Desinformación & 60.700 \\
\hline Competência em Informação & 3.330 \\
\hline Desinformação & 40.000 \\
\hline
\end{tabular}

Fonte: elaborado pelo autor (2020).

Porém, quando a busca é feita com a combinação dos termos "information literacy" e "misinformation", "alfabetización informacional" e "desionformación", bem como "competência em informação" e "desinformação", observa-se uma redução significativa de estudos acadêmicos. Verifica-se queda de maior evidência se observarmos os artigos escritos em português:

Quadro 3 - Resultado da busca com a combinação dos termos "information literacy" e "misinformation", "alfabetización informacional" e "desionformación", bem como "competência em informação" e "desinformação".

\begin{tabular}{|l|l|}
\hline Termo & Resultado \\
\hline "Information Literacy" "Misinformation" & 4.500 \\
\hline "Alfabetización Informacional” "Desionformación" & 367 \\
\hline "Competência em Informação" e "Desinformação" & 266 \\
\hline
\end{tabular}

Fonte: elaborado pelo autor (2020).

Os dados revelam o quanto ainda há para ser explorado da relação entre o processo de desinformação e a carência de competências informacionais do indivíduo.

O que se observa das narrativas que circundam o sistema eletrônico de votação do Brasil é exatamente a falsificação proposital de informações, objetivando enganar pessoas, sobretudo, o 


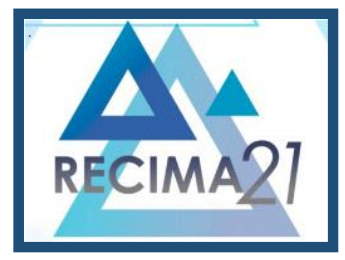

\section{RECIMA21 - REVISTA CIENTÍFICA MULTIDISCIPLINAR}

A DESINFORMAÇÃO NO PROCESSO ELETRÔNICO DE VOTAÇÃO: UMA ANÁLISE SOB O ASPECTO DA COMPETÊNCIA INFORMACIONAL DO INDIVÍDUO João Henrique Koerig eleitor. Quem se beneficia disso? O grupo político-ideológico enganador. Quem perde? A democracia.

Partindo dessa conjuntura, é inegável a urgência em educação informacional, no sentido de desenvolver no usuário/eleitor as competências em informação necessárias para que a expressão de sua vontade não seja contaminada por processos deturpados e fortemente persuasivos.

Diante desse cenário de ameaça à estabilidade democrática, cumpre às instituições, em particular à Justiça Eleitoral, o protagonismo do combate à desinformação nas eleições. Sob pena de testemunhar a perda dos avanços civilizatórios dos quais foi promotora.

No próximo capítulo trataremos desse percurso histórico, bem como apresentaremos dados específicos da pesquisa, no que se refere à desinformação e ao processo de votação eletrônica.

\section{O SISTEMA DE VOTAÇÃO ELETRÔNICA NO BRASIL.}

O processo eleitoral no Brasil, em um sentido mais amplo, diz respeito às fases organizativas das eleições, compreendendo também um breve período posterior. É organizado pela Justiça Eleitoral (JE), em nível municipal, estadual e federal. Na esfera federal, a JE possui como órgão máximo o Tribunal Superior Eleitoral (TSE), com sede em Brasília. Em cada estado da Federação e no Distrito Federal há um Tribunal Regional Eleitoral (TRE), bem como juízes e juntas eleitorais (BRASIL, [2020a], online).

No centro de todos esses atores encontra-se a estrela principal - a urna eletrônica. Usada pela primeira vez nas eleições municipais de 1996, ocasião em que quase um terço da população votou eletronicamente, foi só a partir do ano 2000 que o pleito eletrônico passou a cobrir a totalidade do território nacional.

Desde o início até os dias de hoje, a urna eletrônica passou por diversos aperfeiçoamentos tecnológicos, com o objetivo de garantir aos brasileiros um processo de votação transparente, ágil e seguro. Desenvolvida pela Justiça Eleitoral em parceria com outras instituições, como o Instituto Nacional de Pesquisas Espaciais (INPE), Forças Armadas e o Centro de Pesquisa e Desenvolvimento em Telecomunicações (CPQD), a urna eletrônica é considerada hoje um dos aparelhos mais seguros utilizado em processos de votação. Com o seu advento, somada à informatização da Justiça Eleitoral, foram eliminados vários tipos de fraudes, inconsistências e erros humanos, frequentemente identificados no antigo processo de votação.

Em seu percurso de criação, oito diretrizes foram estabelecidas, a saber:

- Solução universal: registro do voto pelo número do candidato ou do partido.

- Aderência à legislação vigente: máquina criada com possibilidade de evolução para garantir que mudanças na legislação eleitoral não exigissem alterações na urna eletrônica. 


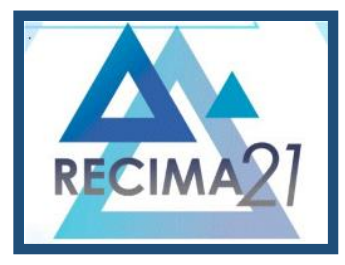

\section{RECIMA21 - REVISTA CIENTÍFICA MULTIDISCIPLINAR}

A DESINFORMAÇÃO NO PROCESSO ELETRÔNICO DE VOTAÇÃO: UMA ANÁLISE SOB O ASPECTO DA COMPETÊNCIA INFORMACIONAL DO INDIVÍDUO

João Henrique Koerig

- Processo amigável: equipamento de fácil utilização pelo eleitor, com a visualização do candidato, na tela de dados, antes da confirmação do voto.

- Custo reduzido: projeto economicamente viável, em função do elevado número de seções eleitorais.

- Perenidade: possibilidade de uso em várias eleições, diminuindo o custo do voto.

- Segurança: eliminação da possibilidade de fraude no registro do voto e na apuração do resultado.

- Facilidade na logística: urna pequena, robusta, de peso reduzido, de fácil armazenamento e transporte.

- Autonomia: uso de bateria nos locais onde não há energia elétrica. (BRASIL, 2016, p. 17).

No que diz respeito à segurança do processo de votação, a urna eletrônica simboliza, ou, pelo menos, deveria simbolizar, a confiança da população nas eleições. São inúmeros (mais de 90) os sistemas eleitorais de segurança nela embutidos que, na prática, representam barreiras físicas e digitais, sequenciadas, que tornam a fraude nas eleições altamente improvável, além de identificar facilmente qualquer tentativa de violação.

Soma-se a isso o fato de ser ela totalmente auditável, e de que outras instituições públicas, como o MPF, Polícia Federal, Tribunal de Contas da União, além da comunidade acadêmica, terem acesso a todos os testes de segurança, processos, certificação dos sistemas, assinaturas digitais, código fonte, cerimônia de lacração da urna etc. É dizer: para que houvesse fraude nas eleições, todas essas autoridades precisariam, necessariamente, ser corrompidas. O que, convenhamos, é pouco provável.

Ocorre que, apesar de toda a segurança contida na urna e da excelente capacidade técnico-operacional da Justiça Eleitoral, o processo de votação eletrônica, de maneira geral, vem sofrendo ataques sob a forma de desinformação.

Em outras palavras, se por um lado não é possível violar fisicamente a urna, nem tampouco os sistemas que envolvem o processo de votação, por outra via se observa o crescimento exponencial de falsas narrativas envolvendo a segurança do pleito. Um verdadeiro bombardeio de Fake News ordenados com um único propósito, deslegitimar o voto eletrônico no Brasil. Mais ainda, colocar o processo eleitoral sob suspeição e enfraquecer valores democráticos.

Com efeito, da análise da coleta de dados bibliográficos no Google Acadêmico contendo os termos "Eleições", "Urna Eletrônica", "Desinformação", "Fake News", compreendida entre os anos 2018 a 2020, período em que se verifica o crescente interesse pelo assunto no ambiente das redes sociais, observa-se um considerável aumento de produção acadêmica, conforme apresenta o quadro 4.

Quadro 4 - Resultado da busca para os termos "Eleições", "Urna Eletrônica”, "Desinformação", "Fake News". 


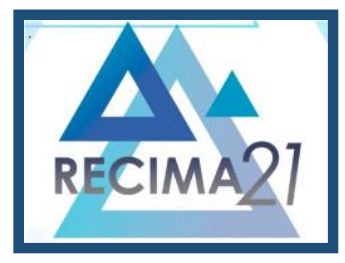

\section{RECIMA21 - REVISTA CIENTÍFICA MULTIDISCIPLINAR}

A DESINFORMAÇÃO NO PROCESSO ELETRÔNICO DE VOTAÇÃO: UMA ANÁLISE SOB O ASPECTO DA COMPETÊNCIA INFORMACIONAL DO INDIVÍDUO

\begin{tabular}{|l|l|l|}
\hline Termo & Período & Resultado \\
\hline "Eleições" "Fake News" & $\begin{array}{l}2018 \text { a } 2020 \\
\text { (Comparação } 2010 \text { a 2018) }\end{array}$ & $\begin{array}{l}3.119 \\
(690)\end{array}$ \\
\hline "Eleições" "Desinformação" & $\begin{array}{l}2018 \text { a } 2020 \\
\text { (Comparação } 2010 \text { a 2018) }\end{array}$ & $\begin{array}{l}\text { (3.330 } \\
(30)\end{array}$ \\
\hline
\end{tabular}

Fonte: elaborado pelo autor (2020).

Verifica-se o aumento expressivo da produção envolvendo o termo Fake News combinado com "Eleições" nos últimos dois anos, ao passo que, quando substituído por "Desinformação", o resultado apresenta aumento proporcional mais modesto. Há de se considerar a contemporaneidade do termo Fake News, o que contribui para sua maior incidência nos últimos anos.

Ao se pesquisar pelo termo "Urna Eletrônica", "Desinformação", "Fake News", o resultado pode ser visualizado no quadro 5 .

Quadro 5 - Resultado da busca para os termos "Urna Eletrônica", "Desinformação", "Fake News".

\begin{tabular}{|l|l|l|}
\hline Termo & Período & Resultado \\
\hline "Urna Eletrônica" “Fake News" & 2018 a 2020 & 81 \\
& (Comparação 2010 a 2018) & $(9)$ \\
\hline "Urna Eletrônica" "Desinformação" & 2018 a 2020 & 62 \\
& (Comparação 2010 a 2018) & $(34)$ \\
\hline
\end{tabular}

Fonte: elaborado pelo autor (2020).

A amostra aponta para a mesma tendência verificada no quadro 4, porém acende 0 alerta para a necessidade de intensificação de produção acadêmica que fomente o conhecimento em torno da segurança da urna eletrônica.

Ao se pesquisar no idioma inglês a combinação dos termos "Election", "Fake News", "Disinformation" observou-se, guardadas as devidas proporções, a mesma tendência de produção.

Quadro 6 - Resultado da busca para os termos "Election", "Fake News", "Disinformation".

\begin{tabular}{|l|l|l|}
\hline Termo & Período & Resultado \\
\hline "Elections" "Fake News" & 2018 a 2020 & 14.300 \\
& (Comparação 2010 a 2018) & $(7.840)$ \\
\hline "Elections" "Disinformation"' & 2018 a 2020 & 8.690 \\
\hline
\end{tabular}




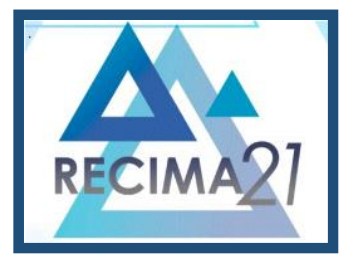

\section{RECIMA21 - REVISTA CIENTÍFICA MULTIDISCIPLINAR}

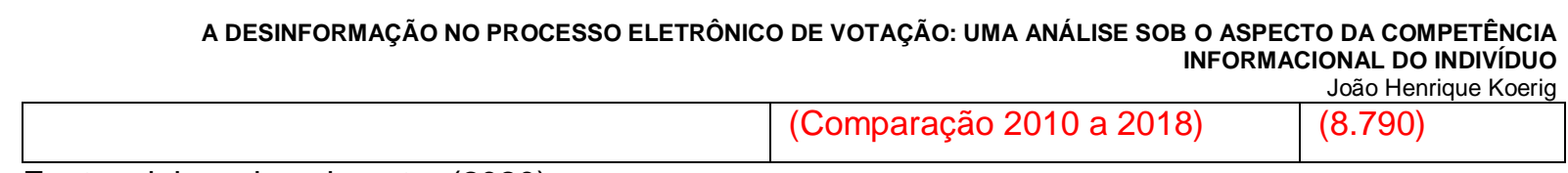

Fonte: elaborado pelo autor (2020).

A partir dos recortes acima, e considerando-se tudo o que foi explanado até o momento, pode-se inferir a necessidade de maior produção acadêmica sobre a temática da desinformação no processo de votação eletrônica, além da urgência em se intensificar ações institucionais, no sentido de informar as pessoas acerca dos avanços democráticos conquistados pelo sistema eleitoral brasileiro.

É com essa ideia de essencialidade de ações educativas que passaremos a discorrer, a seguir, as iniciativas já implementadas pela Justiça Eleitoral, com foco no combate à desinformação.

\subsection{Ações Institucionais de Enfrentamento.}

As eleições brasileiras de 2018 foram emblemáticas em razão de vários acontecimentos, mas nada despertou tanto a atenção das pessoas quanto a imensa quantidade de desinformação que circulou nas redes sociais, bem como a velocidade de sua disseminação. Tal fenômeno acendeu um alerta no Tribunal Superior Eleitoral. Era preciso agir rápido, sob pena de amargar retrocessos no campo democrático. A partir de então, algumas iniciativas foram criadas, além da intensificação de medidas anteriormente iniciadas. Agora, o foco da Justiça Eleitoral se volta para a desinformação.

Percebeu-se, a partir de 2013, com as manifestações que aglomeraram milhões de pessoas por todo o país, seguidas das eleições de 2014 e do impeachment de 2016, o poder de influência e mobilização das mídias sociais. Em 2017, o TSE elaborou a Resolução ํㅜ 23.551, que dispõe sobre a propaganda eleitoral, e que, dentre outros ditames, prevê que a manifestação de pensamento do eleitor é passível de limitação:

Art. 22. É permitida a propaganda eleitoral na internet a partir do dia 16 de agosto do ano da eleição (Lei no 9.504/1997, art. 57-A). § 1ㅇ A livre manifestação do pensamento do eleitor identificado ou identificável na internet somente é passível de limitação quando ocorrer ofensa à honra de terceiros ou divulgação de fatos sabidamente inverídicos. (BRASIL, 2017, online).

O que o TSE fez, na verdade, foi limitar o direito de manifestação do cidadão em favor do interesse público. A partir de então, outras resoluções foram publicadas, no sentido de fortalecer ainda mais a ideia de que a desinformação é ilícita e que aquele que incorrer em sua prática será punido na forma da lei. Apesar de ser esse o papel principal do Poder Judiciário - proibição/punição, também cabe a ele, em especial à Justiça Eleitoral, o papel de educar para o pleno exercício da cidadania. 


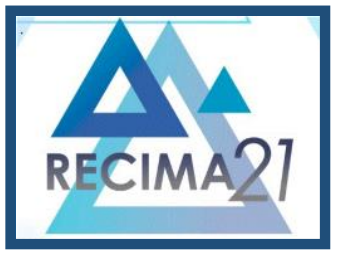

\section{RECIMA21 - REVISTA CIENTÍFICA MULTIDISCIPLINAR}

A DESINFORMAÇÃO NO PROCESSO ELETRÔNICO DE VOTAÇÃO: UMA ANÁLISE SOB O ASPECTO DA COMPETÊNCIA INFORMACIONAL DO INDIVÍDUO

João Henrique Koerig

Nesse sentido, em 2019, o TSE, sob a presidência da Ministra Rosa Weber, lançou o Programa de Enfrentamento à Desinformação com Foco nas Eleições 2020, que contou com a adesão de 49 instituições, entre partidos políticos e entidades públicas e privadas, que se uniram para enfrentar os efeitos negativos provocados pela desinformação no processo eleitoral brasileiro, do qual transcrevo abaixo suas principais diretrizes:

O programa é organizado em seis eixos temáticos: "Organização interna", "Alfabetização Midiática e Informacional", "Contenção à Desinformação", "Identificação e Checagem de Desinformação", "Aperfeiçoamento do Ordenamento Jurídico" e "Aperfeiçoamento de Recursos Tecnológicos".

O eixo "Organização interna" visa à integração e à coordenação entre os níveis e as áreas que compõem a estrutura organizacional da Justiça Eleitoral e a definição das respectivas atribuições contra a desinformação. O de "Alfabetização Midiática e Informacional" busca a capacitação de pessoas para identificar e checar uma desinformação, além de estimular a compreensão sobre o processo eleitoral.

No tópico "Contenção à Desinformação", a meta é instituir medidas concretas para desestimular ações de proliferação de informações falsas. Já com o eixo "Identificação e Checagem de Desinformação", o TSE busca o aperfeiçoamento e novos métodos de identificação de possíveis práticas de disseminação de conteúdos falaciosos.

Por sua vez, o eixo "Aperfeiçoamento do Ordenamento Jurídico" busca a revisão e o aperfeiçoamento do ordenamento jurídico existente sobre a desinformação. E, por fim, o tópico "Aperfeiçoamento de Recursos Tecnológicos", visa ao desenvolvimento e ao aprimoramento de recursos de tecnologia da informação e das comunicações idôneos para a identificação de práticas de desinformação e a divulgação das respectivas contrainformações.

[...] A Corte Eleitoral também mantém uma página específica na internet com diversos conteúdos sobre o tema. No site Desinformação, é possível encontrar esclarecimentos sobre informações falsas divulgadas durante as Eleições Gerais de 2018 envolvendo a Justiça Eleitoral, a urna eletrônica e o voto. O internauta também tem acesso a uma série de vídeos explicativos produzidos pelo Núcleo de Rádio e TV da Assessoria de Comunicação do Tribunal.

[...]

Para fortalecer a segurança da informação e combater a propagação de conteúdo falso na internet, o programa conta com a parceria de quatro das maiores plataformas de mídias sociais e de serviço de mensagens do mundo - Google, Facebook, Twitter e WhatsApp. As empresas comprometeram-se a atuar ativamente para desestimular ações de proliferação de informações falsas e aperfeiçoar métodos de identificação de possíveis práticas de disseminação de conteúdos falaciosos. (BRASIL, 2020b, online).

Observa-se que o TSE vem envidando esforços de combate à desinformação em diferentes frentes de atuação, nas esferas legislativa, judicial e também educacional. A esta última destaca-se o eixo temático do programa chamado "Alfabetização Midiática e Informacional".

Aqui cabem algumas reflexões acerca de toda discussão desenvolvida neste artigo. Se pensarmos a Alfabetização Midiática e Informacional sob a ótica das Competências em Informação e da Gestão da Informação e do Conhecimento, veremos uma potencial contribuição dessas duas áreas para o desenvolvimento da referida iniciativa educacional do TSE. A ação de educar para o desenvolvimento de competências informacionais, utilizando-se o conhecimento acadêmico da matéria, pode representar um salto qualitativo no processo de alfabetização informacional no âmbito 


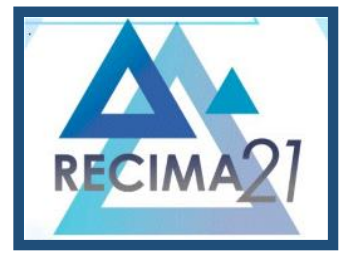

\section{RECIMA21 - REVISTA CIENTÍFICA MULTIDISCIPLINAR}

A DESINFORMAÇÃO NO PROCESSO ELETRÔNICO DE VOTAÇ̃̃O: UMA ANÁLISE SOB O ASPECTO DA COMPETÊNCIA INFORMACIONAL DO INDIVÍDUO João Henrique Koerig da Justiça Eleitoral. Não apenas de seus servidores, mas indo além para propor iniciativas de educação dos eleitores em geral.

Como sugestão, o TSE poderia, em um primeiro momento, firmar parcerias com instituições de ensino, em especial as que possuam programas voltados à Gestão da Informação e do Conhecimento, para capacitação de seus servidores. Essa medida pode ganhar amplitude se repetida por cada Tribunal Regional Eleitoral do país. Em um segundo momento, os tribunais poderiam aproveitar as estruturas de suas Escolas Judiciarias Eleitorais e das Assessorias de Comunicação, para desenvolverem iniciativas educacionais voltadas aos eleitores.

\section{CONSIDERAÇÕES FINAIS.}

O aumento exponencial dos conteúdos informacionais, sobretudo os que circulam nas redes sociais, trouxeram novos desafios para a sociedade contemporânea. Estar preparado para gerir tanta informação é tarefa árdua que precisa ser desenvolvida com o aporte acadêmico necessário. Nesse contexto, a Gestão da Informação e do Conhecimento se apresenta como disciplina indispensável para a construção desse processo educacional. Através de seu conhecimento e de suas práticas, a GIC pode estimular o desenvolvimento de competências em informação nos indivíduos, numa espécie de alfabetização informacional, com vistas ao seu correto uso.

Neste artigo abordou-se o fenômeno da desinformação sob a ótica da Gestão da Informação e do Conhecimento, ressaltando a importância do amadurecimento das competências informacionais das pessoas, para fazer frente à essa verdadeira ameaça à democracia.

Como recorte principal, trouxemos à discussão o aumento expressivo da desinformação nos últimos dois anos, com ênfase no processo de votação eletrônica do Brasil. Foram feitas coletas de dados no portal Google Acadêmico que demonstraram o aumento do interesse pelo tema, além de evidenciar a urgência de maior produção científica relacionada à desinformação e o voto eletrônico. Foram analisadas iniciativas da Justiça Eleitoral no combate a esse processo de deslegitimação do sistema de votação e, por fim, foram propostas iniciativas educacionais no âmbito do TSE e dos Tribunais Regionais Eleitorais.

Importante ressaltar que os resultados aqui apresentados se caracterizam como um ensaio inicial para pesquisas futuras.

\section{REFERÊNCIAS}

ARAÚJO, C. A. Á. Fundamentos da Ciência da Informação: correntes teóricas e o conceito de informação. Perspectivas em Gestão \& Conhecimento, João Pessoa, v. 4, n. 1, p. 57-79, jan./jun. 2014. Disponível em: https://dialnet.unirioja.es/servlet/articulo?codigo=4801007. Acesso em: 21 dez. 2020. 


\section{RECIMA21 - REVISTA CIENTÍFICA MULTIDISCIPLINAR}

A DESINFORMAÇÃO NO PROCESSO ELETRÔNICO DE VOTAÇÃO: UMA ANÁLISE SOB O ASPECTO DA COMPETÊNCIA INFORMACIONAL DO INDIVÍDUO João Henrique Koerig BARBOSA, R. R. Gestão da informação e do conhecimento: origens, polêmicas e perspectivas. Informação \& informação, Londrina, v. 3, n. especial, p. 1-25, 2008.

BOGHARDT, T. Operation INFEKTION - Soviet Bloc Intelligence and Its AIDS Disinformation Campaign. Studies in Intelligence, v. 53, n.4, p. 1-24, dec. 2009. Disponível em: https://www.cia.gov/library/center-for-the-study-of-intelligence/csi-publications/csistudies/studies/vol53no4/soviet-bloc-intelligence-and-its-aids.html. Acesso em: 22 dez. 2020.

BRASIL. Tribunal Superior Eleitoral. Processo eleitoral no Brasil. [2020a]. Disponível em: www.tse.jus.br/eleicoes/processo-eleitoral-brasileiro/funcionamento-do-processo-eleitoral-no-brasil. Acesso em: 23 dez. 2020.

BRASIL. Tribunal Superior Eleitoral. Programa de Enfrentamento à Desinformação com foco nas Eleições 2020 mobiliza instituições. 22 maio 2020b. Disponível em: https://www.tse.jus.br/imprensa/noticias-tse/2020/Maio/programa-de-enfrentamento-a-desinformacaocom-foco-nas-eleicoes-2020-mobiliza-instituicoes. Acesso em: 23 dez. 2020.

BRASIL. Tribunal Superior Eleitoral. Resolução n 23.551, de 18 de dezembro de 2017. Dispõe sobre propaganda eleitoral, utilização e geração do horário gratuito e condutas ilícitas em campanha eleitoral nas eleições. Brasília: TSE, 2017. Disponível em: https://www.tse.jus.br/legislacao/compilada/res/2017/resolucao-no-23-551-de-18-de-dezembro-de2017. Acesso em: 23 dez. 2020.

BRASIL. Tribunal Superior Eleitoral. Urna eletrônica: 20 anos a favor da democracia. Brasília: Tribunal Superior Eleitoral, 2016. Disponível em: https://www.justicaeleitoral.jus.br/arquivos/tse-urnaeletronica-20-anos-a-favor-da-democracia/at download/file. Acesso em: 23 dez. 2020.

BRUCE, C. Seven faces of information literacy in higher education. Brisbane (Austrália): QUT, 1997.

Disponível em: https://www.researchgate.net/profile/Christine Bruce2/publication/239229387 The Seven Faces of Information Literacy/links/0a85e533a01c555789000000/The-Seven-Faces-of-InformationLiteracy.pdf. Acesso em: 23 dez. 2020.

CAREGNATO, S. E. O desenvolvimento de habilidades informacionais: o papel das bibliotecas universitárias no contexto da informação digital em rede. Revista de Biblioteconomia \& Comunicação, Porto Alegre, v. 8, p. 47-55, jan./dez. 2000. Disponível em: http://eprints.rclis.org/11663/1/artigoRBC.pdf. Acesso em: 22 dez. 2020.

CHOO, Chun Wei. A organização do conhecimento: como as organizações usam a informação para criar significados, construir conhecimento e tomar decisões. São Paulo: Editora Senac, 2003.

COMISSÃO EUROPEIA. Combater a desinformação em linha: uma estratégia europeia. Bruxelas: Comissão Européia, 2018. Disponível em: https://eur-lex.europa.eu/legalcontent/PT/TXT/?uri=CELEX\%3A52018DC0236. Acesso em: 02 jan. 2021.

DARNTON, R. A verdadeira história das notícias falsas: séculos antes das redes sociais, os boatos e as mentiras alimentavam pasquins e gazetas na Europa. El País Brasil, [S.I.], 2017. Disponível em: https://brasil.elpais.com/brasil/2017/04/28/cultura/1493389536 863123.html. Acesso em: 23 dez. 2020.

DAVENPORT, Thomas H. Ecologia da informação. São Paulo: Futura, 2001.

DAVENPORT, T. H.; PRUSAK, L. Ecologia da informação: por que só a tecnologia não basta para sucesso na era da informação. São Paulo: Futura, 1998. 


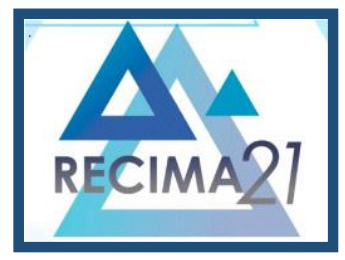

\section{RECIMA21 - REVISTA CIENTÍFICA MULTIDISCIPLINAR}

A DESINFORMAÇÃO NO PROCESSO ELETRÔNICO DE VOTAÇ̃̃O: UMA ANÁLISE SOB O ASPECTO DA COMPETÊNCIA INFORMACIONAL DO INDIVÍDUO João Henrique Koerig

DETLOR, Brian. Information management. International Journal of Information Management, $\mathrm{n}$. 30, p. 103-108, 2010.

DUDZIAK, E. A. Information literacy uma revolução silenciosa: diferentes concepções para a competência em informação. In.: CONGRESSO BRASILEIRO DE BIBLIOTECONOMIA, CIÊNCIA DA INFORMAÇÃO E DOCUMENTAÇÃO, 20., 2002, Fortaleza. Anais [...]. Fortaleza: Febab, 2002. Disponível em: http://eprints.rclis.org/3798/. Acesso em: 23 maio 2020.

G1. Bolsonaro diz: 'Não aceito resultado das eleições diferente da minha eleição'. São Paulo, 28 set. $2018.2 \quad$ Disponível em: https://g1.globo.com/sp/saopaulo/eleicoes/2018/noticia/2018/09/28/bolsonaro-diz-que-nao-aceitara-resultado-diferente-do-queseja-a-minha-eleicao.ghtml. Acesso em: 21 dez. 2020.

HATSCHBACH, M. H. L.; OLINTO, G. Competência em informação: caminhos percorridos e novas trilhas. Revista Brasileira de Biblioteconomia e Documentação, São Paulo, v. 4, n. 1, p. 20-34, jan./jun. 2008.

PARIKH, Shivam B.; PATIL, Vikram; ATREY, Pradeep K. On the origin, proliferation and tone of fake news. 2019. In.: IEEE CONFERENCE ON MULTIMEDIA INFORMATION PROCESSING AND RETRIEVAL (MIPR), 28 a 30 de março de 2019, San Jose, CA, EUA. Anais [...]. Disponível em: 10.1109/MIPR.2019.00031. Acesso em: 22 dez. 2020.

SANCHES, Mariana. Questionado sobre provas, Bolsonaro diz que brasileiros não confiam no sistema eleitoral. BBC Brasil, 10 mar. 2020. Disponível em: https://www.bbc.com/portuguese/brasil51822918. Acesso em: 21 dez. 2020.

SOUZA, E. D.; DIAS, E. J. W.; NASSIF, M. E. A Gestão da Informação e do Conhecimento na Ciência da Informação: perspectivas teóricas e práticas organizacionais. Informação \& Sociedade: Estudos, João Pessoa, v. 21, n. 1, p. 55-70, jan./abr. 2011. Disponível em: https://periodicos.ufpb.br/ojs/index.php/ies/article/view/4039. Acesso em: $21 \mathrm{dez} .2020$.

VALENTIM, M. L. P.; JORGE, C. F. B.; CERETTA-SORIA, M. G. Contribuição da Competência em Informação para os processos de gestão da informação e do conhecimento. Em Questão, v. 20, n. 2, p. 207-231, 2014. Disponível em: http://seer.ufrgs.br/index.php/EmQuestao/article/view/48642/32122. Acesso em: 21 dez. 2020.

VOLKOFF, Vladimir. Pequena história da desinformação: do cavalo de Tróia à internet. Curitiba: Ed. Vila do Príncipe, 2004.

ZATTAR, M. Competência em informação e desinformação: critérios de avaliação do conteúdo das fontes de informação. Liinc em Revista, Rio de Janeiro, v.13, n. 2, p. 285-293, 2017. Disponível em: http://revista.ibict.br/liinc/article/view/4075/3385. Acesso em: 24 dez. 2020. 